\title{
Localized Swelling Inhomogeneity Detection in Lithium Ion Cells Using Multi-Dimensional Laser Scanning
}

\author{
Yan Zhao, $\circledast^{1,=}$ Franz B. Spingler, $\oplus^{2,=, *, z}$ Yatish Patel, $\oplus^{1}$ Gregory J. Offer, $\circledast^{1, * *}$ \\ and Andreas Jossen $\circledR^{2}$
}

${ }^{1}$ Department of Mechanical Engineering, Imperial College London, London SW7 2AZ, United Kingdom

${ }^{2}$ Institute of Electrical Energy Storage Technology, Technical University of Munich (TUM), 80333 Munich, Germany

\begin{abstract}
The safety, performance and lifetime of lithium-ion cells are critical for the acceptance of electric vehicles (EVs) but the detection of cell quality issues non-destructively is difficult. In this work, we demonstrate the use of a multi-dimensional laser scanning method to detect local inhomogeneities. Commercially available cells with Nickel Cobalt Manganese (NMC) cathode are cycled at various charge and discharge rates, while 2D battery displacement measurements are taken using the laser scanning system. Significant local swelling points are found on the cell during the discharge phase, the magnitude of swelling can be up to $2 \%$ of the cell thickness. The results show that the swelling can be aggravated by a combination of slow charge rate and fast discharge rate. Disassembly of the cells shows that the swelling points are matched with the location of 'adhesive-like' material found on the electrode surfaces. Scanning Electron Microscope (SEM) images show that the material is potentially blocking the electrodes and separators at these locations. We therefore present laser-scanning displacement as a valuable tool for defect/inhomogeneity detection.

(c) The Author(s) 2019. Published by ECS. This is an open access article distributed under the terms of the Creative Commons Attribution 4.0 License (CC BY, http://creativecommons.org/licenses/by/4.0/), which permits unrestricted reuse of the work in any medium, provided the original work is properly cited. [DOI: 10.1149/2.0011902jes]

(cc) BY
\end{abstract}

Manuscript submitted August 20, 2018; revised manuscript received November 30, 2018. Published January 4, 2019.

It is widely assumed that economies of scale will help solve the cost problem of lithium ion batteries in automotive and home or grid storage applications. ${ }^{1-3}$ Apart from reducing sourcing costs of primary materials, a large portion of the savings from scaling up production is realized through improving manufacturing processes. ${ }^{4}$ The most important characteristics of lithium-ion cells, namely safety, performance, and lifetime, are determined by their manufacturing quality as much as the material composition of the active and passive components and the cell design. As of today, a limited amount of research on the effects of imperfect manufacturing processes on cell performance has been published. In Mohanty et al., ${ }^{5}$ the cell performance implications and the effect of electrode manufacturing defects were studied. In Cannarella et al. ${ }^{6}$ it was shown that deliberately manufactured pore closure in separators led to lithium plating on the graphite anode around the compressed areas. Both studies found that the negative impact of a defect depends disproportionally on its size, such that very small local defects may not lead to secondary defects like lithium plating during operation at all. Defect size dependence on lithium plating has been further investigated in Liu et al. ${ }^{7}$

In this paper, we show how local, macroscopic inhomogeneities in a commercial lithium-ion pouch cell that possibly originate from the manufacturing process, lead to unexpected local volume changes. Volume changes of lithium ion cells during operation can be attributed to several mechanisms. Firstly, intercalation materials used in lithium ion cells undergo volume changes as a function of their degree of lithiation. ${ }^{8-11}$ Secondly, every component of a cell swells and contracts as a function of its temperature and individual thermal expansion coefficient. ${ }^{12-14}$ Other reasons for volume changes are morphology changes in the porous electrodes and separators, side reactions that produce gas and/or passivating layers ${ }^{15,16}$ and unwanted surface film forming mechanisms like lithium plating. ${ }^{16,17}$ From a practical point of view, understanding volume changes in lithium ion batteries is essential to ensure safe operation in applications where batteries are fitted into confined spaces, which is the case for virtually all mobile applications. Furthermore, dilation or resulting pressure is a relatively easily accessible quantity that holds information about the inner state of a lithium-ion cell, possibly making it a valuable input parameter for battery management systems. ${ }^{18-20}$

Various approaches have been presented to measure the dilation of lithium-ion cells in operation. In Lee et al. ${ }^{21}$ a thickness gauge

\footnotetext{
$=$ These authors contributed equally to this work.

*Electrochemical Society Student Member.

**Electrochemical Society Member.

${ }^{\mathrm{z} E}$-mail: franz.spingler@tum.de
}

was used to measure the average thickness change of a commercial pouch cell compressed between two plates. More accurate displacement sensors touching on a single location on the cell surface were used in Refs. 21-23 and on various locations simultaneously on both sides of the cell in Ref. 24. Local resolution of cell dilation has been achieved by 3-D image correlation ${ }^{25}$ and laser triangulation. ${ }^{26-28}$ Other non-touching measurements include $\mathrm{X}$-ray tomography ${ }^{29}$ and neutron diffraction. $^{15}$

Dilation measurements have been used to detect lithium plating ${ }^{22}$ and, by making use of local resolution across the cell surface, to investigate inhomogeneous aging. ${ }^{27,30}$ Here, we investigate and discuss the relationship of macroscopic inhomogeneities observable in fresh cells to anomalous local volume expansion and local deposits on the electrodes found post-mortem.

\section{Experimental}

Cells characterization and cycling.-The cells used in this study are commercial $5 \mathrm{Ah}$ pouch cells with a nickel-manganesecobalt-lithium oxide (NMC) cathode and graphite anode of the type SLPB $11543140 \mathrm{H} 5$ by Kokam Ltd. Cell characteristics are summarized in Table I. For each of the tests described in Table II, a fresh cell in condition as received from the supplier was used after the initial characterization. In a preliminary study, a wide range of charge and discharge rates were used across different cells to ensure the results observed were repeatable.

Before each test, the initial characterization test was performed on each fresh cell to ensure that the cells were in condition as specified by the manufacturer. The fresh cells were cycled 10 times with $100 \%$ depth of discharge at $0.5 \mathrm{C}$ using constant current, constant voltage $(\mathrm{CC}-\mathrm{CV})$ charge and constant current $(\mathrm{CC})$ discharge protocol, followed by a CC-CV discharge capacity determination at $0.1 \mathrm{C}$. All CV phases were interrupted when the current fell below $0.05 \mathrm{C}$ or $0.25 \mathrm{~A}$.

Cycling was done at current rates ranging from $0.2 \mathrm{C}$ to $4 \mathrm{C}$ using a CC-CV charge and CC discharge protocol. Full cycles at various combinations of charge and discharge rates were conducted to assess the rate dependency of local swelling. Chamber temperature was $15^{\circ} \mathrm{C}$ in all experiments.

2-D thickness scan.-Two laser heads directed at both sides of the cell are mounted on a linear axis aligned in parallel to the cell surface as shown in Figure 1. Each laser head performs a continuous triangulation measurement while the slide is moved along the cell surface. The slide moves at a speed of $2 \mathrm{~cm} / \mathrm{s}$, so the entire surface of the Kokam cell is captured in $6 \mathrm{~s}$. The differential of the height 
Table I. Characteristics of Kokam SLPB11543140H5 pouch cells used in this study.

Outer dimensions ( $\mathrm{LxWxH})$

Anode sheet size $(\mathrm{LxWxH})$

Cathode sheet size $(\mathrm{LxWxH})$

Current collector thickness

Coating thickness

Stack design

Max. charge/discharge rate

Upper and lower cutoff volt.

Rated capacity

Gravimetric energy density
$142.5 \mathrm{~mm} \times 51 \mathrm{~mm} \times 11.7 \mathrm{~mm}$ (data sheet)

$111 \mathrm{~mm} \times 39 \mathrm{~mm} \times 97 \mu \mathrm{m}$ (measured)

$110 \mathrm{~mm} \times 38 \mathrm{~mm} \times 79 \mu \mathrm{m}$ (measured)

Anode: $\sim 21 \mu \mathrm{m} /$ Cathode: $\sim 21 \mu \mathrm{m}$ (measured)

Anode: $\sim 76 \mu \mathrm{m} /$ Cathode: $\sim 58 \mu \mathrm{m}$ (measured)

50 double side coated anodes, 49 double side coated cathodes +2 single side coated cathodes. Separator Z-folded. $5 \mathrm{C} / 20 \mathrm{C}$

$4.2 \mathrm{~V} / 2.7 \mathrm{~V}$

$5 \mathrm{Ah}\left(0.5 \mathrm{C}, 25^{\circ} \mathrm{C}\right)$

$140 \mathrm{Wh} / \mathrm{kg}$ profiles recorded by each laser head is the cell thickness. The setup is encased in a temperature-controlled chamber. The cell is connected to a BaSyTec CTS battery cycler. An infrared temperature sensor tracks the surface temperature at the center of the cell. More details about the test bench can be found in previous studies. ${ }^{26,27,30}$ The scan area was partitioned into 96 rectangles and the thickness was averaged across the surface of every rectangle in a pre-processing step. In these rectangles, thickness is resolved within $+/-1 \mu \mathrm{m}$ at a reproducibility of $+/-2 \mu \mathrm{m}$ including dismounting and re-mounting of a test cell. As the cell edges of the Kokam pouch cells are bent down and their shape varies slightly from cell to cell, the scan area excluded a few millimeters of the cell edge to each side to get consistent results.

Post-mortem and SEM.-Before disassembly, cells were discharged with CC-CV to $2.7 \mathrm{~V}$ and rested for one to two hours. Disassembly of cells took place inside an argon filled glove box $(<0.1$ ppm $\mathrm{O}_{2} / \mathrm{H}_{2} \mathrm{O}$ ). Photographs of the cell stack and of single electrodes were taken immediately after disassembly. Separator and electrode probes were left to dry inside the glove box and then transferred out, where they were exposed to normal laboratory atmosphere. Separator probes were gold-sputtered in vacuum atmosphere for $90 \mathrm{~s}$ at $10 \mathrm{~mA}$ using a Cressington 108 series bench top SEM sputter coater before they were introduced into the SEM. A JCM-6000Plus Tabletop SEM by JEOL was used for electrode probes, separators were investigated using a ZEISS NV40 Crossbeam Workstation.

\section{Results}

Initial measurements.-Cells were charged with a CC-CV procedure to $4.2 \mathrm{~V}$, rested for 30mins, and then discharged with $1 \mathrm{C} \mathrm{CC}$ to $2.7 \mathrm{~V}$, while the laser measurement was taken. Figure 2 shows snap shots of the normalized thickness distribution change during the $1 \mathrm{C}$ $\mathrm{CC}$ discharge step. To show the thickness change clearly, the thickness at the start of the discharge was subtracted from the raw measurement. Previous work ${ }^{31}$ shows that the cell thickness change roughly follows the state of charge change, where the cell thickness increases during charge and decreases during the discharge process. At time $776 \mathrm{~s}$ in Figure 2, four spots on the cell started to swell, while the rest of the cell contracted as expected. The approximate $x-y$ coordinates of the swelling points are point $1(-33,5)$; point $2(35,7)$; point $3(-33,-13)$ and point $4(35,-14)$. These points and the surrounding area continued to swell as the discharge continued. At point $(-33,5)$ the thickness increased from $0.034 \mathrm{~mm}$ to $0.062 \mathrm{~mm}$ between $776 \mathrm{~s}$ and $2716 \mathrm{~s}$. The thickness of the rest of the cell continued to decrease with decreasing SoC. At time $2716 \mathrm{~s}$, the cell thickness at the center $(0,0)$ was reduced

Table II. Cycling conditions of Kokam SLPB11543140H5 cell. Al experiments were conducted at $15^{\circ} \mathrm{C}$ chamber temperature.

\begin{tabular}{llll} 
& \multicolumn{1}{c}{ Charge rate } & \multicolumn{1}{c}{ Discharge rate } & Comments \\
\hline Fig. 2 & $1 \mathrm{C}$ & $1 \mathrm{C}$ & Full cycle \\
Fig. 3/Fig. 4 & $0.2 \mathrm{C} / 0.5 \mathrm{C} / 1 \mathrm{C} / 2 \mathrm{C}$ & $1 \mathrm{C}$ & Full cycle \\
Fig. 5 & $0.2 \mathrm{C} / 0.5 \mathrm{C} / 1 \mathrm{C} / 2 \mathrm{C}$ & $0.2 \mathrm{C} / 0.5 \mathrm{C} / 1 \mathrm{C} / 2 \mathrm{C}$ & Full cycle \\
Fig. 6 & $0.2 \mathrm{C} / 2 \mathrm{C}$ & $2 \mathrm{C} / 0.2 \mathrm{C}$ & Full cycle
\end{tabular}

by $0.049 \mathrm{~mm}$. As a result, the difference in thickness between center $(0,0)$ and the swelling point $(-33,5)$ was around $0.1 \mathrm{~mm}$. The thickness change behavior at these swelling points is unexpected; therefore more investigation was done to understand this behavior.

Cycling at different charge and discharge rates.-In this section, the effects of charge and discharge rate on the swelling points are investigated. A fresh cell was cycled at different charge rates followed by a CC discharge, and vice versa.

Effect of the charge rate.-Cells were charged using a CC-CV protocol at increasing current rates, $0.2 \mathrm{C}, 0.5 \mathrm{C}, 1 \mathrm{C}$ and $2 \mathrm{C}$. Each charging event was followed by a $1 \mathrm{C}$ discharge. Figure 3 shows the thickness change as a function of time. The average thickness (black line) increased upon charging and decreased upon discharge. The average thickness is defined as the average of all recorded local

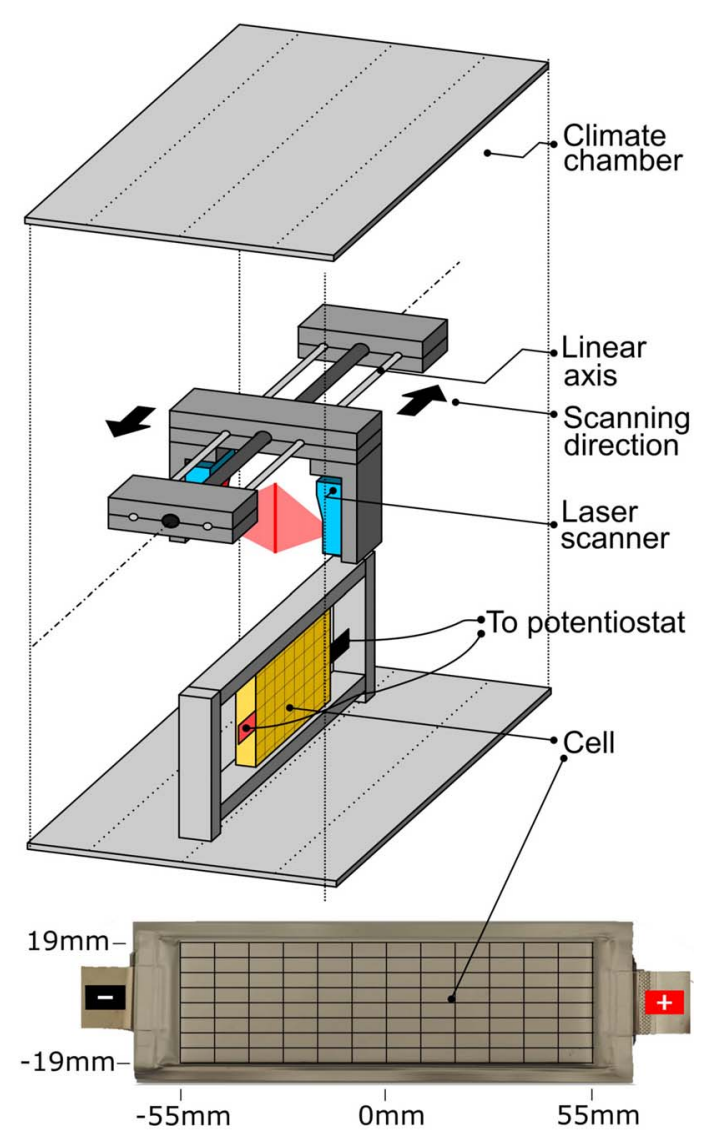

Figure 1. 2-D thickness scan setup used in this study. One laser head on each side of the cell scans the cell surface while moving in parallel to the cell surface. The cell surface is partitioned into 96 rectangles whose area-average thickness is computed after every scan. 


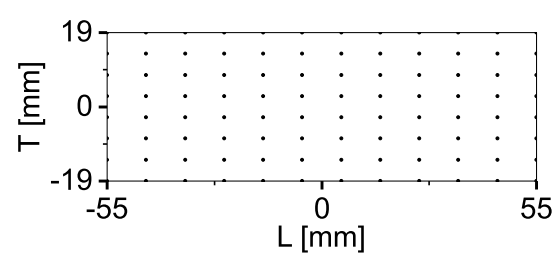

Time $=0 \mathrm{~s}$

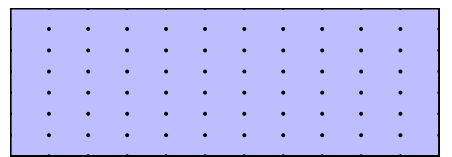

Time $=388 \mathrm{~s}$

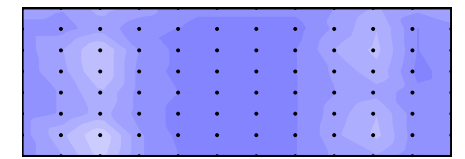

Time $=776 \mathrm{~s}$

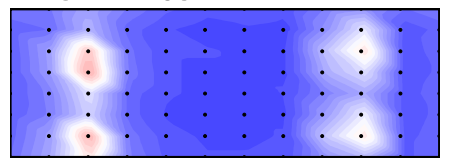

Time $=1164 \mathrm{~s}$

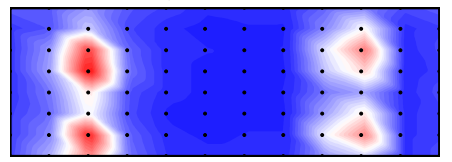

Time $=1552 \mathrm{~s}$

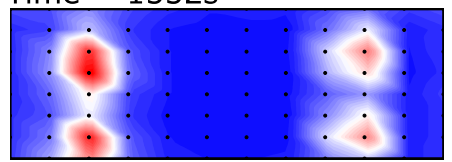

Time $=1940 \mathrm{~s}$

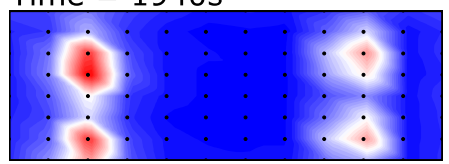

Time $=2328 \mathrm{~s}$

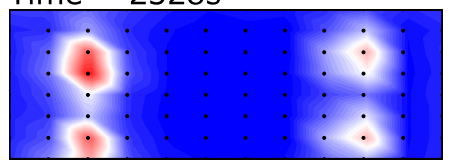

Time $=2716 \mathrm{~s}$



\section{Thickness change $[\mu \mathrm{m}]$}

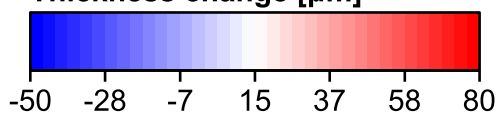

Figure 2. Normalized cell thickness distribution change during the $1 \mathrm{C}$ discharge following 1CCC-CV charging, where $\mathrm{y}$-axis is the length and $\mathrm{x}$-axis is the width of the cell in $\mathrm{mm}$.

thickness measurements at a given point in time. The shape of the average thickness resembled that of the voltage curves. The thickness varied by approximately $0.23 \mathrm{~mm}$ ( $2 \%$ of the total thickness). The slight difference between different charge rates could be caused by variation in temperature and utilized SoC window.

At the four swelling points, local thickness revealed thickness overshoots close to the end of charge that increased in magnitude with

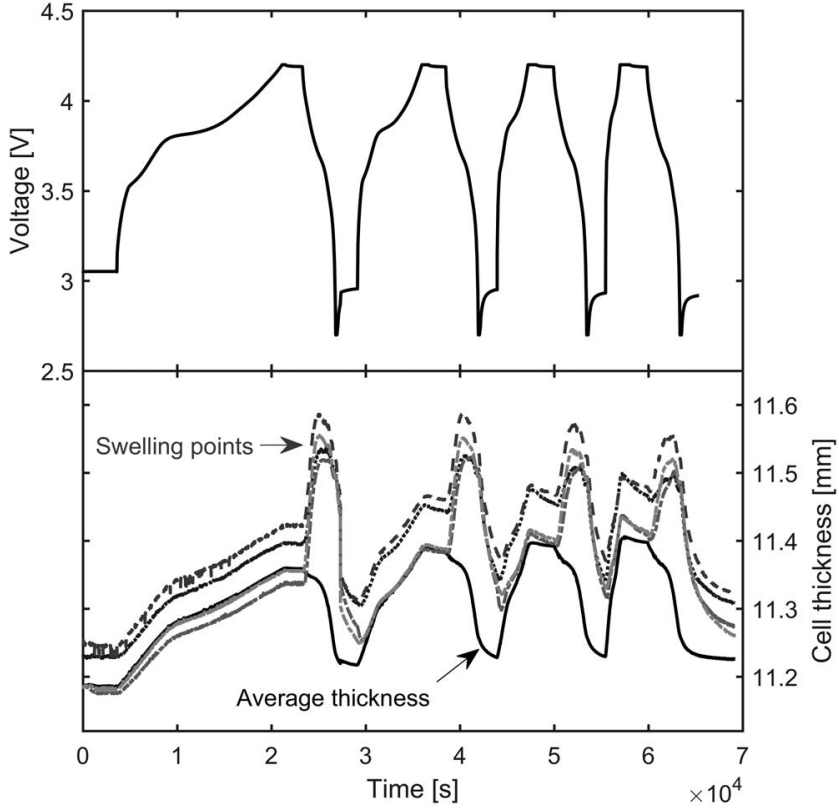

Figure 3. The thickness change as function of time with different charge rates $(0.2 \mathrm{C}, 0.5 \mathrm{C}, 1 \mathrm{C}$ and $2 \mathrm{C})$ - cell voltage(top) and thickness (bottom) at selected points, where the black line is the cell average thickness and the gray lines are thickness at swelling point $1-4$.

the charging current. These thickness overshoots have been shown in a previous study and could be linked to partly reversible lithium plating. ${ }^{30}$ Interestingly, at the beginning of the discharge phase, the points again swelled sharply. Thickness only started to decrease once the SoC dropped below approximately $30 \%-40 \%$.

Thickness change as a function of preceding charge rates is shown in Figure 4 where the average thickness is plotted in gray and the swelling point 1 is plotted in black. On average, the cell contracted by

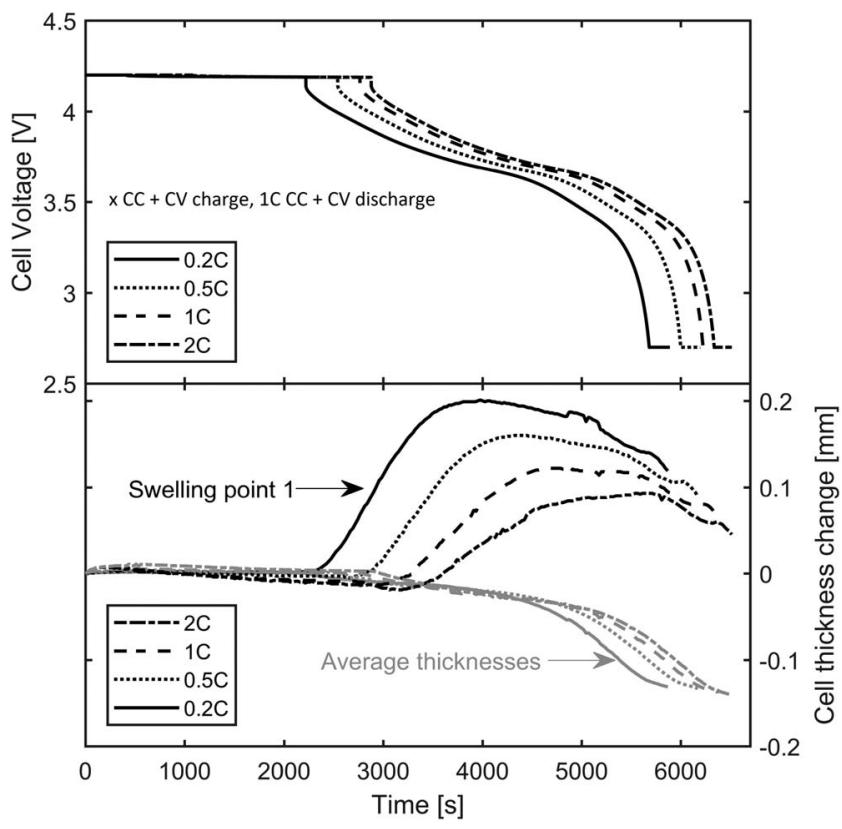

Figure 4. Comparison of the thickness change between swelling point (SP) 1 and the average cell thickness change during the $1 \mathrm{C}$ discharge phase after charging at $0.2 \mathrm{C}, 0.5 \mathrm{C}, 1 \mathrm{C}$ and $2 \mathrm{C}$. The gray line is the cell average thickness and the black lines are thickness at swelling point 1 , cell voltage (top) and thickness (bottom). 


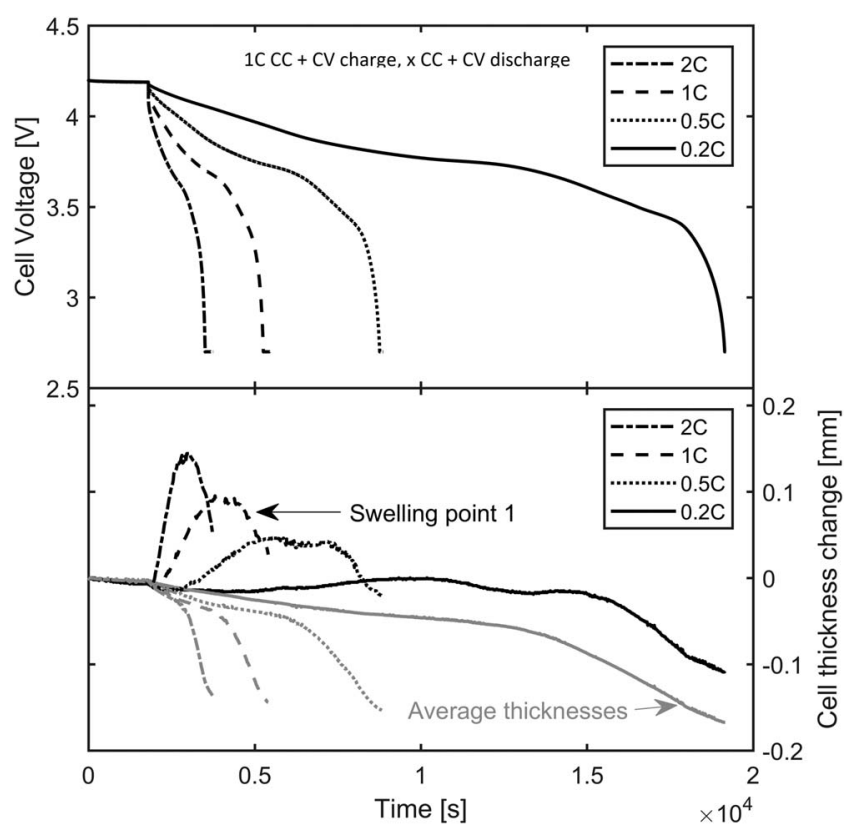

Figure 5. Comparison of thickness change between swell point 1 (SP1) and the average cell thickness change during the discharge $(0.2 \mathrm{C}, 0.5 \mathrm{C}, 1 \mathrm{C}$ and 2C) phase following the $1 \mathrm{C}$ charge, where the black line is the cell average thickness and the gray lines are thickness at swelling point 1, cell voltage (top) and thickness (bottom).

approximately $0.14 \mathrm{~mm}$ during the $1 \mathrm{C}$ discharge. When it followed a $0.2 \mathrm{C}$ charge, the $1 \mathrm{C}$ discharge resulted in $0.012 \mathrm{~mm}$ more contraction than when it followed a $2 \mathrm{C}$ charge. This may be attributed to greater thermal expansion and contraction in the $2 \mathrm{C}$ charge case.

At swelling point 1 , thickness started to increase at the beginning of discharge. The point started to contract after approximately $1500 \mathrm{~s}$. Expansion upon discharge was most significant following the $0.2 \mathrm{C}$ charge and the least significant following the $2 \mathrm{C}$ charge. The maximum local thickness increase was $0.198 \mathrm{~mm}, 0.158 \mathrm{~mm}, 0.122 \mathrm{~mm}$ and $0.095 \mathrm{~mm}$ following charge rates of $0.2 \mathrm{C}, 0.5 \mathrm{C}, 1 \mathrm{C}$ and $2 \mathrm{C}$, respectively. At the end of discharge, the local thickness values were still $+0.117 \mathrm{~mm},+0.087 \mathrm{~mm},+0.062 \mathrm{~mm}$ and $+0.047 \mathrm{~mm}$.
As swelling points expanded further while the rest of the cell contracted, the maximum difference in thickness change during the process was over $0.2 \mathrm{~mm}$ by the end of the discharge. The difference of $0.2 \mathrm{~mm}$ amounts to around $2 \%$ of total cell thickness. This could lead to significant mechanical stress within the electrode layers, and potentially result in mechanically driven damages.

Effect of the discharge rate.-In this section, the effect of the discharge rate on the behavior of the swelling points is presented. In each experiment, cells were charged at a rate of $1 \mathrm{C}$, followed by discharge at rates of $0.2 \mathrm{C}, 0.5 \mathrm{C}, 1 \mathrm{C}$ and $2 \mathrm{C}$. The thickness change during the discharge phase is shown in Figure 5, where the average thickness is plotted in gray and the swelling point 1 is plotted in black.

At all discharge rates, the average thickness decreased. The shape of the thickness curve resembled the shape of the voltage curve. The thickness changes at the end of discharge are similar, the thickness decreased by approximately $0.15 \mathrm{~mm}$. At a discharge rate of $0.2 \mathrm{C}$, the cell contracted by $0.167 \mathrm{~mm}$ in comparison to $0.136 \mathrm{~mm}$ at the end of the $2 \mathrm{C}$ discharge. The larger discharge current caused the cell's terminal voltage to reach the cutoff voltage sooner, limiting the usable capacity. The reduced capacity utilization could have caused the cell to contract less at the end of discharge at higher rates.

At the swelling point, thickness change during the discharge phase was positively correlated with the current rate. The maximum expansion at $0.2 \mathrm{C}, 1 \mathrm{C}, 0.5 \mathrm{C}$ and $2 \mathrm{C}$ were $0.144 \mathrm{~mm}, 0.095 \mathrm{~mm}, 0.046 \mathrm{~mm}$ and $0.003 \mathrm{~mm}$. The swelling point started to contract when SoC dropped below approximately $60 \%$ SoC. At the end of the discharge, swelling point expansion were $0.058 \mathrm{~mm}, 0.027 \mathrm{~mm},-0.022 \mathrm{~mm}$ and $-0.108 \mathrm{~mm}$. Interestingly, the discharge rate had the opposite effect as the charge rate. The higher the discharge rate, the higher the local swelling following the same charge event.

So far, the results indicate that the swelling points expand more significantly when charged slowly and the opposite is true for the discharge rate. To validate this observation, two tests were performed: 1. Charge $0.2 \mathrm{C}+$ Discharge $2 \mathrm{C} ; 2$. Charge $2 \mathrm{C}+$ Discharge $0.2 \mathrm{C}$. The hypothesis was that the experiment 1 should indicate the most significant swelling under discharge and the experiments 2 would show the least amount of swelling.

Figure 6 shows the results of experiment 1 and 2. In experiment 1 , the thickness increased significantly during the $2 \mathrm{C}$ discharge phase at the swelling points. The thickness increase peaked at approximately $0.18 \mathrm{~mm}$ during discharge. By the end of the discharge phase, thickness at the swelling points were approximately $0.11 \mathrm{~mm}$ higher
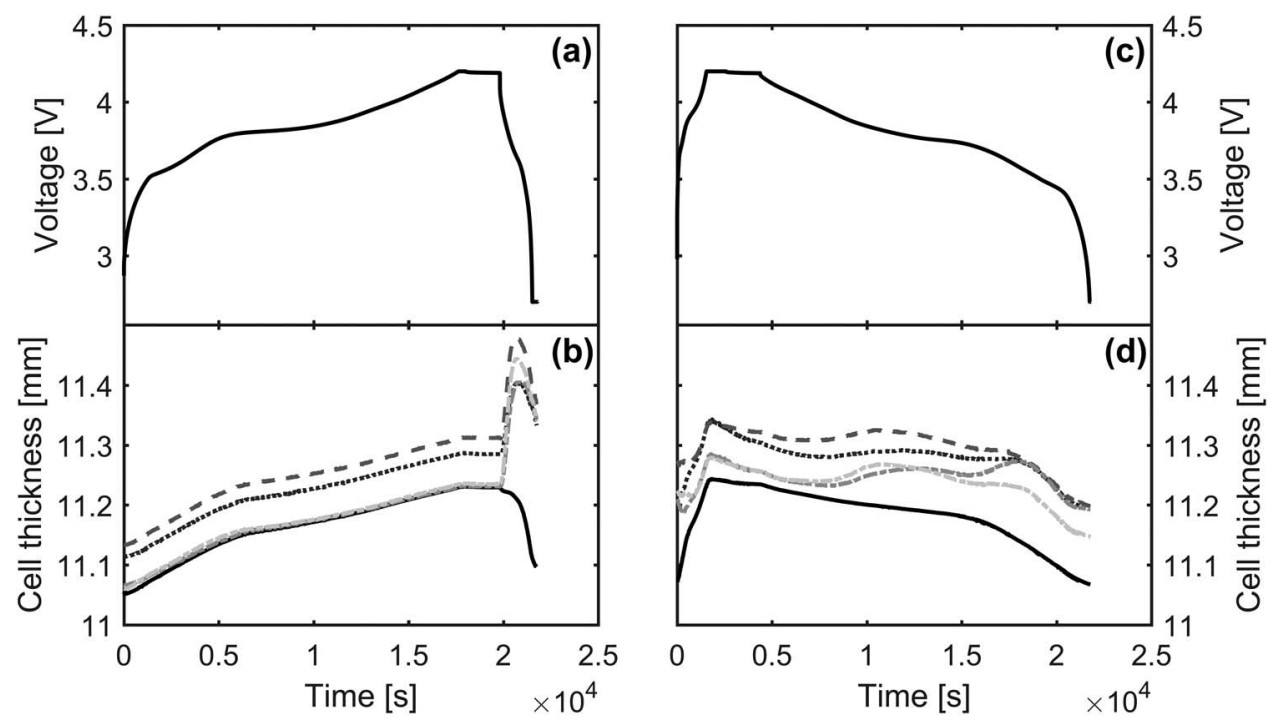

Figure 6. Voltage and thickness: experiment 1(charge @ 0.2C + discharge @ 2C), (a) experiment 1 voltage measurement, (b) thickness of swelling points (gray lines) and average thickness (black); experiment 2 (charge @ 2C+discharge @ 0.2C), (c) experiment 2 voltage measurement, (d) thickness of swelling point(gray lines) and average thickness (black). 
a) Fresh cell stack

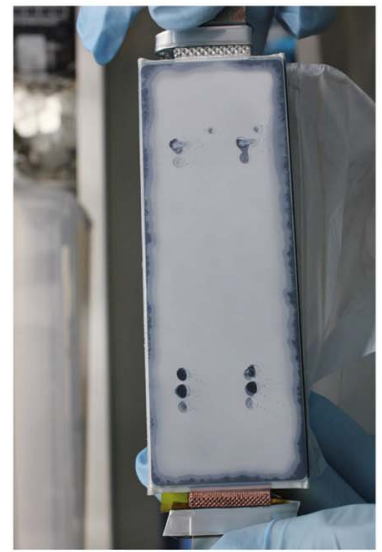

b) adhesive spot sep./an.

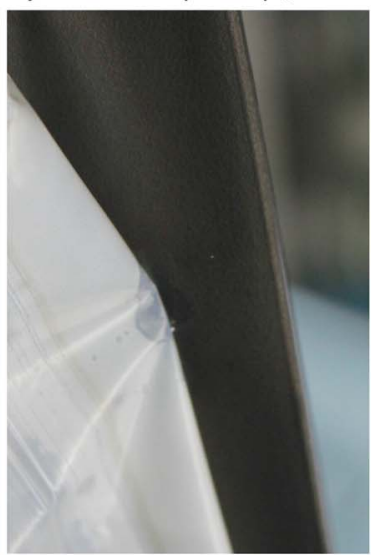

c) spot pattern

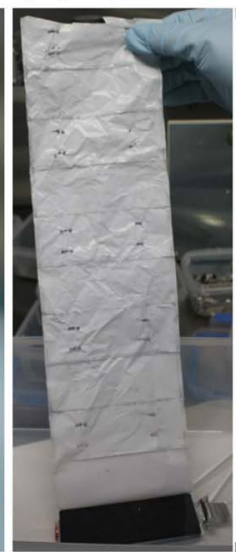

d) fresh vs. cycled anode

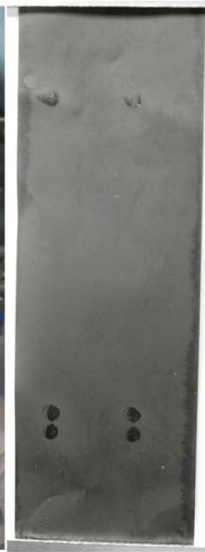

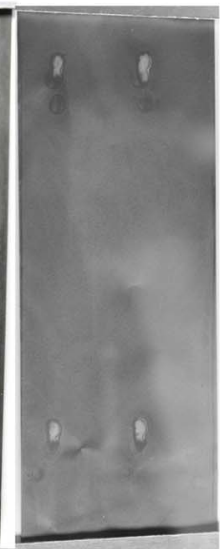

Figure 7. Post-mortem of the cell, (a) fresh cell stack; (b) adhesive like spots; (c) spots pattern on cycled separator roll; (d) spots on anode surface for fresh and cycled cell.

compared to the start of discharge. In comparison, the average thickness of the cell decreased by $0.13 \mathrm{~mm}$ during the discharge phase.

In experiment 2 , where the minimum swelling was expected, the thickness at the swelling points decreased by $0.15 \mathrm{~mm}$ during discharge. The average thickness decreased by $0.17 \mathrm{~mm}$ at the same time. However, the thickness at the swelling points decreased initially, followed by small increases at $3.9 \mathrm{~V}$ and $3.5 \mathrm{~V}$. In contrast, the cell average thickness decreased uniformly without increase during the discharge phase.

In accordance with our hypothesis, experiment 1 showed significantly more swelling during the discharge phase. Thickness at swelling points were $0.15 \mathrm{~mm}$ higher in comparison to experiment 2 .

Post-mortem inspection.-Experimental results showed that low rate charging, high rate discharging causes four areas on the cell surface to swell abnormally during discharge. A fresh and a cycled cell were disassembled inside an argon filled glove box to examine the physical appearance of the cell material. The cycled cell underwent ca. 40 cycles and various current rates and had $98 \%$ remaining capacity before it was disassembled.

Upon unwrapping the electrode stack, four discolored spots were discovered on the separator surface. The spots were located at co- ordinates $(-33,5),(35,7),(-33,-13)$ and $(35,-14)$. The locations of these spots are consistent with the location of the swelling points measured by the laser scan. The spots appeared to be contaminated by adhesive-like gel as shown in Figure $7 \mathrm{~b}$. The spot appeared on alternate layers of the separator as shown in Figure 7c. This pattern was repeated in the entire stack. Figure $7 d$ shows the swelling spots of a fresh and a cycled cell. On the fresh anodes, dark spots are visible, these match the locations of the spots on the separator. When unwrapping the cell stack, separator and electrodes adhered to one another at these spots. On and around the spots, gray deposit appears to have accumulated on the anodes of the cycled cell. The zoom inlet in Figure 7d shows a light-gray colored spot with a distinct seam of a different gray on its right side. This is consistent with the numerous disassembly observations made with the same and similar cell types from the same manufacturer by both battery research groups at TUM and Imperial College over the past 3 years. ${ }^{30,32,33}$ The adhesive-like contaminants were constantly found. These include cells in fresh and cycled condition. Cells were purchased from different suppliers and at different times. It could be that the contaminant is indeed an adhesive that is used on purpose in the manufacturing process to hold the layers (electrodes, separator) in place during stacking and subsequent handling. a) Anode top view

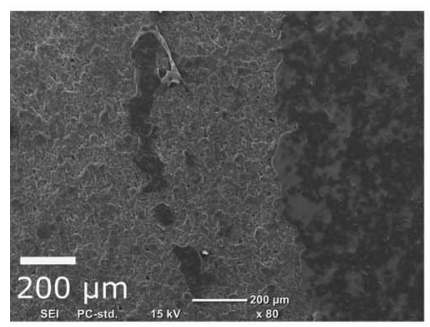

d) Separator top view

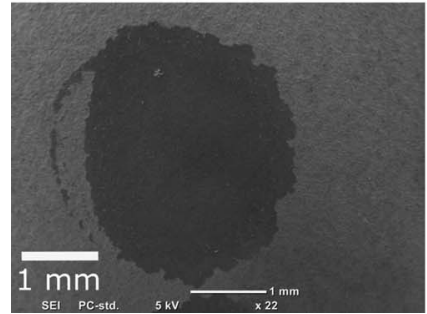

b) Anode cross-section

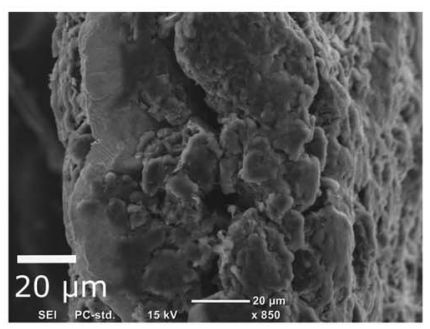

e) Separator top view outside SP

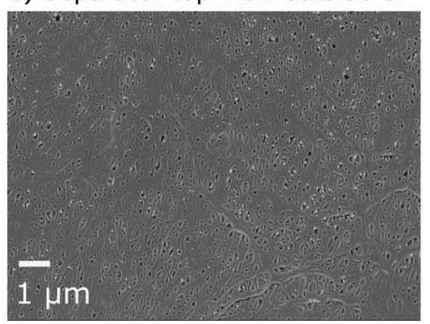

c) Anode cross-section SP

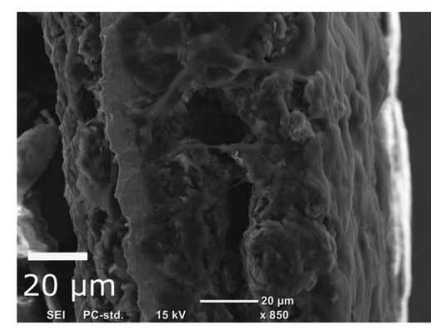

f) Separator top view inside SP

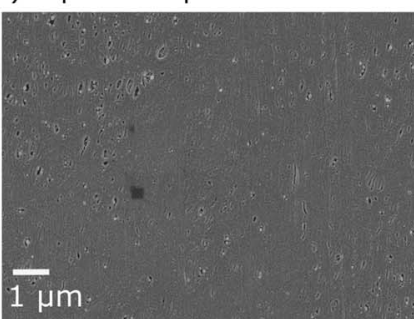

Figure 8. SEM imaging of the disassembled cells. An 'adhesive' like contaminant is visible on the anode surface at the location of the swelling points in a) and c) and on the separator in d). Details of the separator outside (e) and inside (f) the swelling point suggest that the contaminant filled the separator pores. 
Table III. Thermal expansion coefficient calculation for 'normal' part of cell.

\begin{tabular}{|c|c|c|c|c|c|}
\hline & Total thickness [mm] & Percentage of total & Expansion coefficient & Proportional coefficient & Reference \\
\hline $\mathrm{CC} \mathrm{Cu}$ & 1.05 & $9.0 \%$ & $1.60 \times 10^{-5}$ & $1.44 \times 10^{-6}$ & 38 \\
\hline $\mathrm{CC} \mathrm{Al}$ & 1.07 & $9.2 \%$ & $2.30 \times 10^{-5}$ & $2.11 \times 10^{-6}$ & 38 \\
\hline Anode & 3.95 & $33.8 \%$ & $5.50 \times 10^{-5}$ & $1.86 \times 10^{-5}$ & 39 \\
\hline Cathode & 2.90 & $24.8 \%$ & $5.50 \times 10^{-5}$ & $1.36 \times 10^{-5}$ & Assumed same as Anode ${ }^{39}$ \\
\hline Separator/SP & 2.40 & $20.5 \%$ & $2.50 \times 10^{-3}$ & $5.13 \times 10^{-4}$ & 40 \\
\hline Casing & 0.32 & $2.7 \%$ & & & \\
\hline Total & 11.69 & & & $5.49 \times 10^{-4}$ & \\
\hline
\end{tabular}

To investigate the contaminant on the electrode/separator structure, SEM imaging was used. Figure 8 a shows the top view of the boundary between swelling spots and the rest of the electrode surface. The contaminant appears to have filled the gaps between individual graphite particles and made the originally rough surface smooth. The crosssectional image of the 'normal' anode and the swelling point further confirms this observation. It appears that the contaminant blocked this part of the electrode surface. The blockage could limit the ion transport and reaction rate. At worst, the entire region could have become inactive. It is difficult to determine the effect of the contaminant from the SEM images alone.

On the separator, the contaminant appears to have closed the pores on the separator, when comparing Figure 8e and Figure 8f. The pore closure could lead to slower ionic transport through the separator. As shown by Cannarella et. al, pore closure can cause high local currents and overpotentials in the surrounding electrode area, rendering it susceptible to lithium plating. ${ }^{6}$

\section{Discussion}

In this section, we present hypotheses that could explain the experimental findings: Local swelling overshoots at the end of charge, local swelling at the beginning of discharge, localized gray deposits on the anode surface and adhesive-like contaminants found on the separator and both positive and negative electrodes.

Close to the end of charge, we observed that the cell thickness temporarily was higher than the final thickness after charging and relaxation, which has been referred to as swelling overshoot. The magnitude of these swelling overshoots was positively correlated with charging current and they were more pronounced at those locations where the adhesive-like contaminants were found. Local swelling overshoots comparable to those found here have been linked to lithium plating in a previous study. ${ }^{30}$ Lithium plating on the graphite anode is thermodynamically favorable when the local potential, measured vs. a virtual $\mathrm{Li} / \mathrm{Li}+$ reference, falls below $0 \mathrm{~V}$. This situation can result from limited transport in the liquid and solid phases ${ }^{34,35}$ and sluggish charge transfer kinetics ${ }^{36}$ at the liquid-solid-interface. It has been shown experimentally that deliberately induced ion transport restrictions in separators lead to lithium plating on graphite anodes at the edges of the manipulated areas. ${ }^{6,7}$ Numerical analysis has shown that this is due to increased current densities in the vicinity of the manipulated areas that compensate for their restricted transport contribution. ${ }^{6}$ In our case, we may assume that the adhesive-like contaminants at the swelling points caused local transport non-uniformity. The swelling points would have had a significantly higher transport limitation due to the blockage. As in the above reports, these effects could have induced local current density fluctuation and led to lithium plating. The localized gray deposits, which were found on the anode surface, especially the distinct seam around the spot that can be seen in Figure 7d, support this hypothesis.

As for the local swelling during discharge, the experimental results, as shown in Figure 5, indicate that the swelling positively correlated with the discharge rate after the cell was charged at same rate, i. e. a larger discharge current led to higher swelling. The cell thickness is influenced by both $\mathrm{SoC}$ reduction and temperature increase. SoC reduction will lead to a reduction in cell thickness and temperature increase will lead to an increase due to thermal expansion. Overall, the cell thickness decreases as it is being discharged. As for the swelling points, it was observed that the thickness increases significantly at the start of the discharge. To explain this observation, we hypothesize the following:

1. the adhesive like contaminants are preventing the swelling points from discharging locally at the same rate as the rest of the cell. This would lead to less reduction in SoC as the discharge starts locally at swelling points and, as a result, less thickness reduction.

2. a greater discharge rate causes more heat generation, leading to higher thermal expansion. The difference in material composition at the swelling points could also contribute to a greater thermal expansion.

Overall, the swelling points' thickness would increase on discharge if the thermal expansion could not be compensated for by the SoC-dependent thickness reduction when discharge is hampered in these areas. Combined with the thermal expansion a different thickness change pattern can be expected. Figure 9 illustrates the correlation of cell temperature increase with the normalized thickness evolution at the swelling spots for different discharge rates. The thickness at SP1 were normalized by the average thickness of the cell. At different C-rates, the normalized expansion at the SP1 and average cell expansion correlates well with the temperature increase. This correlation supports the hypothesis that the containment has a higher thermal expansion coefficient.

A simple calculation of thermal expansion during a $2 \mathrm{C}$ discharge is performed for both the 'normal' and the swelling parts of the cell. Equation 1 is used to calculate the overall thermal expansion coefficient of the cell from the individual components. A $4{ }^{\circ} \mathrm{C}$ temperature increase was measured during $2 \mathrm{C}$ discharge. Table III shows the

Table IV. Thermal expansion coefficient calculation for swelling point (SP).

\begin{tabular}{|c|c|c|c|c|c|}
\hline & Total thickness [mm] & Percentage of total & Expansion coefficient & Proportional coefficient & Reference \\
\hline $\mathrm{CC} \mathrm{Cu}$ & 1.05 & $9.0 \%$ & $1.60 \times 10^{-5}$ & $1.44 \times 10^{-6}$ & 38 \\
\hline $\mathrm{CC} \mathrm{Al}$ & 1.07 & $9.2 \%$ & $2.30 \times 10^{-5}$ & $2.11 \times 10^{-6}$ & 38 \\
\hline Anode & 3.95 & $33.8 \%$ & $5.50 \times 10^{-5}$ & $1.86 \times 10^{-5}$ & 39 \\
\hline Cathode & 2.90 & $24.8 \%$ & $5.50 \times 10^{-5}$ & $1.36 \times 10^{-5}$ & Assumed same as Anode ${ }^{39}$ \\
\hline Separator/SP & 2.40 & $20.5 \%$ & $9.00 \times 10^{-3}$ & $1.85 \times 10^{-3}$ & Fitted \\
\hline Casing & 0.32 & $2.7 \%$ & & & \\
\hline Total & 11.69 & & & $1.88 \times 10^{-3}$ & \\
\hline
\end{tabular}




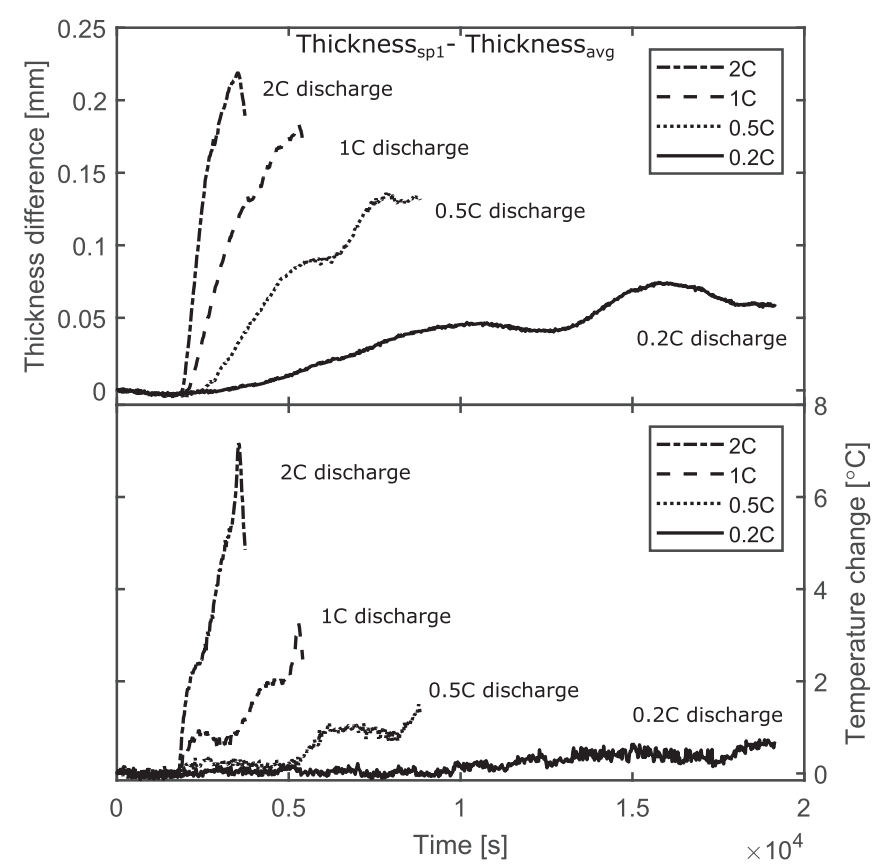

Figure 9. Comparison of the normalized thickness change at swelling point 1 (SP1). The cell surface temperature increases during discharge $(0.2 \mathrm{C}, 0.5 \mathrm{C}$, $1 \mathrm{C}$ and $2 \mathrm{C}$ ) following the 1C charge: difference in thickness between SP1 and the average thickness (top) and temperature increase (bottom).

calculation of the thermal expansion coefficient for the 'normal' part of the cell. Based on the thermal expansion coefficient for individual components, the overall equivalent expansion coefficient is $5.49 \times$ $10^{-4} 1 / \mathrm{K}$. This corresponds to a $0.025 \mathrm{~mm}$ expansion for the $4^{\circ} \mathrm{C}$ temperature increase during a $2 \mathrm{C}$ discharge. The calculated equivalent expansion coefficient is consistent with measurements made in our previous study and with literature. ${ }^{14,30}$

Assuming there is no thickness reduction due to SoC change at the swelling point, it would need to be $6^{\circ} \mathrm{C}$ hotter than the rest of the cell using the calculated expansion coefficient. As the cell is made of thermally conductive materials (aluminum and copper), we consider a hot spot of this magnitude to be unlikely. In our previous work, Zhao et al. showed that the maximum temperature gradient within a cell of the same type is approximately $2.5^{\circ} \mathrm{C}$ at the end of a $2 \mathrm{C}$ discharge under quiet aggressive thermal boundary conditions realized via metallic heat sinks. ${ }^{37}$ In this work, all cell surfaces (electrode stack and electrical terminals) were exposed to ambient air, which should result in a much smaller thermal gradient than $2.5^{\circ} \mathrm{C}$. Hence an alternative hypothesis must be considered. Based on the above, it is hypothesized that the swelling point may have a higher thermal expansion coefficient than the 'normal' parts of the cell.

$$
\alpha_{\text {total }} L_{\text {total }}=\sum \alpha_{i} L_{i}
$$

In Equation 1, $\alpha_{\text {totla }}$ is the overall thermal expansion coefficient, $L_{\text {total }}$ is the total cell thickness, $\alpha_{i}$ is the thermal expansion coefficient of individual components, and $L_{i}$ is the thickness of individual components.

Table IV shows the value of the thermal expansion coefficient for the swelling point fitted to match the experiment if no local hotspot is assumed. It was found that a total thermal expansion coefficient of $1.88 \times 10^{-3} 1 / \mathrm{K}$ would result in a $0.09 \mathrm{~mm}$ expansion during the discharge. This simple calculation demonstrates that if the contaminant has a higher thermal expansion coefficient than the separator, it could be the cause of the behavior observed during discharge. However, it was not possible to characterize the thermal expansion coefficient of the contaminants and/or modified region of the cell during this study. We consider the local swelling on discharge likely to result from a combination of both effects, a thermal expansion coefficient that differs from the rest of the cell and a local hotspot.

\section{Conclusions}

Through a combination of cycling experiments, thickness measurements and post-mortem findings, this work shows that local inhomogeneities in a commercial pouch cell lead to irregular local volume changes and promote local lithium plating. It is hypothesized that the inhomogeneities in the form of an adhesive-like contaminant result from the manufacturing process of the cells. Analysis is provided that shows that the local expansion on discharge, which had not been observed in previous studies using a different cell, ${ }^{30}$ could result from a relatively high thermal expansion coefficient of that contaminants and/or localized heating. Local lithium plating found post-mortem in the vicinity of the adhesive-like contaminants and SEM images of the separator and electrodes suggests that the contaminants restricted the ion pathways of the separator and/or blocks access to the electrodes' surfaces. This would confirm existing theories about separator pore closure and localized lithium plating, ${ }^{6,7}$ which were based on experimental cells, by means of a commercially available cell. Further work is required to characterize the exact composition and property of the contaminant.

This work also demonstrates that the proposed local thickness measurement is a powerful non-destructive cell quality evaluation tool. We suggest that the laser scanning tool could be used to validate cell designs, to evaluate manufacturing processes and in manufacturing quality control.

\section{Acknowledgments}

We acknowledge the funding support received from the BIAMImperial Center for Materials Characterisation, Processing and Modelling at Imperial College London, from the Imperial-TUM Global Fellows Program and from the Federal Ministry of Education and Research of Germany (BMBF) under grant number 03XP0138B. We thank Jonathan Becker of WSI in Garching for his great help with SEM imaging and Prof. Dr. Karl-Heinz Pettinger of HAW Landshut for insightful discussions.

\section{ORCID}

Yan Zhao (1) https://orcid.org/0000-0002-3211-6740

Franz B. Spingler (1) https://orcid.org/0000-0002-6523-3986

Yatish Patel (1) https://orcid.org/0000-0001-7828-5315

Gregory J. Offer (D) https://orcid.org/0000-0003-1324-8366

Andreas Jossen (10) https://orcid.org/0000-0003-0964-1405

\section{References}

1. B. Nykvist and M. Nilsson, Nature Climate Change, 5, 329 EP - (2015).

2. M. Weiss, M. K. Patel, M. Junginger, A. Perujo, P. Bonnel, and G. van Grootveld, Energy Policy, 48, 374 (2012).

3. L. Gaines and R. Cuenca, Costs of lithium-ion batteries for vehicles, (2000).

4. D. L. Wood, J. Li, and C. Daniel, Journal of Power Sources, 275, 234 (2015).

5. D. Mohanty, E. Hockaday, J. Li, D. K. Hensley, C. Daniel, and D. L. Wood, J. Power Sources, 312, 70 (2016).

6. J. Cannarella and C. B. Arnold, J. Electrochem. Soc., 162(7), A1365 (2015)

7. X. M. Liu, A. Fang, M. P. Haataja, and C. B. Arnold, J. Electrochem. Soc., 165(5), A1147 (2018)

8. M. Hahn, H. Buqa, P. W. Ruch, D. Goers, M. E. Spahr, J. Ufheil, P. Novák, and R. Kötz, Electrochem. Solid-State Lett., 11(9), A151 (2008).

9. M. Winter, G. H. Wrodnigg, J. O. Besenhard, W. Biberacher, and P. Novák, J. Electrochem. Soc., 147(7), 2427 (2000).

10. O. Dolotko, A. Senyshyn, M. J. Mühlbauer, K. Nikolowski, and H. Ehrenberg, J. Power Sources, 255, 197 (2014).

11. Kejie Zhao, Mechanics of Electrodes in Lithium-ion Batteries, Cambridge (14.6.2012).

12. D. K. L. Tsang, B. J. Marsden, S. L. Fok, and G. Hall, Carbon, 43(14), 2902 (2005). 
13. E. A. Kellett and B. P. Richards, Journal of Nuclear Materials, 12(2), 184 (1964).

14. K.-Y. Oh and B. I. Epureanu, Journal of Power Sources, 303, 86 (2016).

15. J. B. Siegel, A. G. Stefanopoulou, P. Hagans, Y. Ding, and D. Gorsich, J. Electrochem. Soc., 160(8), A1031 (2013).

16. M. Petzl, M. Kasper, and M. A. Danzer, J. Power Sources, 275, 799 (2015).

17. M. Lewerenz, A. Warnecke, and D. U. Sauer, Journal of Power Sources, 369, 122 (2017).

18. N. A. Samad, Y. Kim, J. B. Siegel, and A. G. Stefanopoulou, J. Electrochem. Soc., 163(8), A1584 (2016).

19. S. Mohan, Y. Kim, J. B. Siegel, N. A. Samad, and A. G. Stefanopoulou, J. Electrochem. Soc., 161(14), A2222 (2014).

20. J. Cannarella and C. B. Arnold, J. Power Sources, 269, 7 (2014).

21. J. H. Lee, H. M. Lee, and S. Ahn, J. Power Sources, 119-121, 833 (2003).

22. B. Bitzer and A. Gruhle, J. Power Sources, 262, 297 (2014).

23. I. Soga and Y. Kinoshita, Japanese Journal of Applied Physics, 41(Part 1, No. 11A), 6616 (2002).

24. K.-Y. Oh, J. B. Siegel, L. Secondo, S. U. Kim, N. A. Samad, J. Qin, D. Anderson, K. Garikipati, A. Knobloch, B. I. Epureanu, C. W. Monroe, and A. Stefanopoulou, J. Power Sources, 267, 197 (2014).

25. P. K. Leung, C. Moreno, I. Masters, S. Hazra, B. Conde, M. R. Mohamed, R. J. Dashwood, and R. Bhagat, J. Power Sources, 271, 82 (2014).

26. B. Rieger, S. F. Schuster, S. V. Erhard, P. J. Osswald, A. Rheinfeld, C. Willmann, and A. Jossen, Journal of Energy Storage, 8, 1 (2016).
27. J. Sturm, F. B. Spingler, B. Rieger, A. Rheinfeld, and A. Jossen, J. Electrochem. Soc., 164(7), A1342 (2017).

28. C. Birkenmaier, B. Bitzer, M. Harzheim, A. Hintennach, and T. Schleid, J. Electrochem. Soc., 162(14), A2646 (2015).

29. X. Wang, Y. Sone, and S. Kuwajima, J. Electrochem. Soc., 151(2), A273 (2004).

30. F. B. Spingler, W. Wittmann, J. Sturm, B. Rieger, and A. Jossen, Journal of Power Sources, 393, 152 (2018)

31. B. Rieger, S. V. Erhard, K. Rumpf, and A. Jossen, J. Electrochem. Soc., 163(8), A1566 (2016).

32. I. A. Hunt, Y. Zhao, Y. Patel, and J. Offer, J. Electrochem. Soc., 163(9), A1846 (2016).

33. Y. Zhao, Y. Patel, I. A. Hunt, K. M. Kareh, A. A. Holland, C. Korte, J. P. Dear, Y. Yue, and G. J. Offer, Journal of Energy Storage, 13, 296 (2017).

34. K. Zaghib, F. Brochu, A. Guerfi, and K. Kinoshita, J. Power Sources, 103(1), 140 (2001).

35. S. S. Zhang, K. Xu, and T. R. Jow, Electrochimica Acta, 48(3), 241 (2002).

36. J. Li, C. F. Yuan, Z. H. Guo, Z. A. Zhang, Y. Q. Lai, and J. Liu, Electrochimica Acta, 59, 69 (2012).

37. Y. Zhao, Y. Patel, T. Zhang, and G. J. Offer, J. Electrochem. Soc., 165(13), A3169 (2018).

38. Schaeffler, Technisches Taschenbuch, (2014).

39. Chetna Bindra, Vera A. Nalimova, Dmitry E. Sklovsky, William A. Kamitakahara, and John E. Fischer, Phys. Rev., B 57, 5182 (1998).

40. James E. Mark, The Polymer Data Handbook. 